\title{
APEGO AO LUGAR E AO COMPORTAMENTO PRÓ-AMBIENTAL: O RACIONAMENTO DE ÁGUA EM QUESTÃO
}

Natália de David Klavdianos

Mestre no Programa de Pós-Graduação em Psicologia Social, do Trabalho e das Organizações, Instituto de Psicologia - Universidade de Brasília, Brasil.

Isolda de Araújo Gunther

Mestre no Programa de Pós-Graduação em Psicologia Social, do Trabalho e das Organizações, Instituto de Psicologia - Universidade de Brasília, Brasil.
RESUMO: A escassez de água tem colocado em risco a saúde humana, sendo necessárias ações de conservação. Racionar água é uma medida adotada por cidades sob esse risco. O objetivo do estudo foi identificar quais as variáveis psicológicas, sociodemográficas e situacionais que dificultam ou auxiliam moradores no período de racionamento a conservar este recurso. A amostra foi escolhida por conveniência, constituída por 103 adultos, que responderam um questionário contendo escalas de favorabilidade às medidas de racionamento e apego ao lugar. Foram utilizados Grupos focais para acessar suas percepções sobre o racionamento. Os dados das escalas foram analisados estatisticamente, e a análise de conteúdo foi realizada nos grupos focais. Os resultados indicaram diferenças em apego ao lugar e favorabilidade dependendo do local estudado e do nível socioeconômico dos participantes. Conclui-se que os aspectos de apego ao lugar se relacionam ao comportamento pró-ambiental.

PALAVRAS-CHAVE: Conservação de água; Mudanças climáticas e saúde; Apego ao lugar.

\section{PLACE ATTACHMENT AND PRO-ENVIRONMENT BEHAVIOR: DISCUSSING WATER RATIONING}

\begin{abstract}
Water scarcity has put to risk human health and conservation actions have become urgent. Water rationing has been employed in several cities to cope with the issue. Current analysis identifies the psychological, sociodemographic and situational variables that make difficult or help people during the rationing period so that the resource could be preserved. A convenience sample of 103 adults answered a questionnaire with favorability scales to rationing measures and bonds to sites. Focal groups were employed to access perceptions on rationing. Scale data were analyzed statistically and content analysis was employed in focal groups. Results reveal difference in bonding and favorability that depends on the site analyzed and the participants' socioeconomic level. Bonding aspects are related to pro-environmental behavior.
\end{abstract}

KEY WORDS: Water conservation; Climate change and health; Place attachment.

\section{INTRODUÇÃO}

Autor correspondente:

Natalia de David Klavdianos

nataliadedavid@hotmail.com
O Painel Intergovernamental sobre Mudanças Climáticas (IPCC) prevê que até 2025 1,8 bilhão pessoas estarão vivendo em áreas de absoluta escassez de água, com graves consequências para a saúde e 
a qualidade de vida humanas, para os meios de produção de alimentos e para a economia e política de nações ${ }^{1}$. Além de fatores climáticos, ações humanas contribuem direta e indiretamente para o agravamento deste quadro, a exemplo da agricultura e do tipo de alimentação, administração e construção de reservatórios de água, de despejo de poluentes, do aumento da população, da indústria e meios de produção, do uso de tecnologias, do estilo de vida e a visão e dos valores atribuídos à água e seu uso.

Uma vez que o agravamento da escassez de recursos naturais, e em especial dos recursos hídricos, se deve ao comportamento humano de uso não sustentável dos mesmos, a mitigação de mudanças climáticas e a preservação do meio ambiente somente será possível a partir de mudança de comportamentos, percepções, atitudes, estilos de vida e práticas culturais relativos à proteção ambiental ${ }^{2}$. Algumas cidades brasileiras afetadas pelos fenômenos de conturbação e crescimento acelerado da população, nas quais não houve planejamento suficiente para uso da terra e dos recursos são afetadas pelo agravamento do quadro de escassez de água na cidade, fazendo-se necessária a implementação de medidas de racionamento de água.

Mudanças de comportamento humano são tema da psicologia e mais especificamente da psicologia ambiental, ao se tratar de comportamentos em relação ao ambiente físico, ou às relações pessoa-ambiente. A psicologia ambiental é uma área interdisciplinar, que tem como uma de suas prioridades a promoção de comportamentos ditos "amigos do ambiente", ou seja, busca compreender como indivíduos, grupos e comunidades podem adotar comportamentos em relação a recursos ambientais de maneira que essa e futuras gerações possuam um ambiente seguro e de qualidade para se viver ${ }^{3}$.

Em situações de crise, como a do risco de escassez de água, medidas de conservação em larga escala foram colocadas em prática para toda a população. Nesse caso, para que as medidas de restrição sejam efetivas não é suficiente conhecer apenas quais são os motivadores individuais para a conservação de água, mas também como indivíduos e comunidades percebem a implantação do racionamento, em seus ambientes sociofísicos específicos, e quais as dificuldades encontradas em aderir aos mesmos.

As medidas de racionamento em uma cidade brasileira afetaram a população principalmente em seus locais de residência. O lugar onde se mora, seja ele a casa, o bairro, e até mesmo a cidade, é considerado importante não apenas pelas suas funções de proteção física e de suprimento das necessidades básicas. A vinculação afetiva formada com um lugar é denominada "apego ao lugar", e caracteriza-se por ser um laço experimentado como positivo entre uma pessoa e um lugar, formado a partir de comportamentos, afetos e cognições construídas entre indivíduos ou grupos e seus ambientes sociofísicos, proporcionando um estado de bem-estar psicológico e o desejo de permanecer perto deste local ${ }^{4}$.

Estudos em psicologia ambiental vêm explorando a relação positiva que pode existir entre apego ao lugar e comportamentos pró-ambientais em relação ao lugar onde se mora, e preocupação com o meio ambiente, em específico com recursos naturais presentes onde se vive $^{5,6}$. Ao se sentir pertencente a um lugar e atribuir valor emocional e simbólico a ele, um indivíduo ou grupo também tende a se apropriar deste espaço e agir no sentido de mantê-lo conservado, para que o suprimento das necessidades físicas, ecológicas, psicológicas e sociais que este ambiente oferece não sejam modificadas (Longhinotti-Felippe \& Kuhnen, 2012 ${ }^{11}$ ).

Assim, questiona-se qual seria o papel do apego ao lugar onde se mora na percepção da necessidade das medidas de racionamento de água por moradores da cidade, frente ao risco de falta de água.

\section{COMPORTAMENTO PRÓ-AMBIENTAL}

O conceito de "comportamento pró-ambiental" pode ser entendido como algum comportamento que beneficia o meio ambiente, melhora a qualidade ambiental, ou que de forma consciente prejudica o meio ambiente o mínimo possível ${ }^{7,8}$. Investigações sobre quais fatores são determinantes para a promoção de comportamentos próambientais, entendidos como comportamentos que visam à proteção ou diminuição de danos ao ambiente, têm sido recorrentes e um dos principais focos da psicologia ambiental nos últimos anos ${ }^{910}$. 
Em psicologia, estudos relacionados à conservação de água visam formular, adaptar e explorar estratégias que possam ser efetivas na conservação de recursos hídricos, identificando quais os fatores situacionais, como idade, gênero, renda, educação, e tipo de moradia, cultura e normas, e quais os determinantes psicológicos, incluindo-se motivações financeiras, valores, crenças, habilidades de conservação, atitudes, percepções, expectativas, e hábitos, para citar alguns, podem influenciar a adoção de comportamentos que visam à proteção ambiental ${ }^{11,12}$. Ao buscar compreender $\mathrm{e}$ questionar pensamentos, sentimentos e comportamentos que afetam o meio ambiente, a psicologia pode facilitar mudanças às escolhas feitas por indivíduos, grupos e governos sobre a proteção ao meio ambiente ${ }^{13}$.

A variedade existente de comportamentos, práticas e ações pró-ambientais implicam também na diversidade de variáveis que influenciam sua ocorrência. As variáveis que influenciam especificamente o consumo responsável de água costumam se dividir em variáveis sociodemográficas, fatores pessoais, ou psicológicos e fatores situacionais ${ }^{11}$. Para que a promoção de consumo responsável de água seja eficaz, como é o objetivo do racionamento de água, é necessário identificar quais desses fatores podem ser úteis.

Variáveis psicológicas que podem influenciar a adoção de comportamentos pró-ambientais incluem conhecimento sobre ações necessárias para se mitigar os riscos ambientais existentes ${ }^{14} ;$ atitudes favoráveis a práticas de conservaçã̃o ${ }^{15}$; valores e crenças pró-ambientais ${ }^{16}$; percepção dos riscos ambientais ${ }^{17}$; motivação para se agir de maneira a conservar recursos ${ }^{11}$; emoções positivas que incentivem práticas ambientais, ou emoções negativas que impeçam práticas não sustentáveis ${ }^{18}$.

Variáveis sociodemográficas e situacionais podem incluir idade ${ }^{19}$; gênero ${ }^{20}$; o fato de se morar em casas ou apartamentos, e se a residência é própria ou alugada ${ }^{21}$; nível socioeconômico ${ }^{11}$; normas sociais ${ }^{22}$; e proximidade do local de risco ${ }^{23}$.
APEGO AO LUGAR DE MORADIA E COMPORTAMENTO PRÓ-AMBIENTAL

Adaptações psicológicas e estruturais são cada vez mais necessárias para lidar com mudanças climáticas e suas consequências, o que muitas vezes implicará em mudanças nas relações pessoa-ambiente. Visto a importância do lugar de moradia e o apego desenvolvido em relação a ele, a percepção de que esse local está em risco pode implicar na emergência de ações e adaptações para que o lugar e o vínculo afetivo a ele permaneçam ${ }^{24}$.

Pesquisas sugerem que quanto mais forte $o$ apego ao lugar onde se vive, maior a preocupação e incidência de comportamentos pró-ambientais ${ }^{5}$; mais relatos de atitudes pró-ambientais ${ }^{25}$; maior o apoio a políticas de preservação ambiental e de implantação de formas alternativas de energia ${ }^{26}$.

Em vista ao que foi abordado acerca de comportamentos pró-ambientais e apego ao lugar de moradia, esta pesquisa pretendeu explorar apego ao lugar de moradia e favorabilidade ao racionamento de água, a fim de se identificar a existência de uma relação positiva entre os dois construtos, e quais as barreiras e facilitadores para maior aderência ao programa.

\section{METODOLOGIA}

A presente pesquisa foi submetida à apreciação do Comitê de Ética, e foi aprovada anteriormente ao início das coletas de dados, com Certificado de Apresentação para Apreciação Ética de número 87276318.4.0000.5540.

\section{PARTICIPANTES}

Os participantes tanto nos grupos focais quanto os respondentes aos questionários foram residentes de casas em duas localidades de uma cidade brasileira, Localidade 1 e Localidade 2, e maiores de 18 anos. Vinte e cinco pessoas participaram dos grupos focais, em abril de 2018. Foi realizado um grupo focal na Localidade 1, com sete participantes, sendo dois homens e cinco mulheres, e média de idade de 50 anos. Em Localidade 2 foram realizados dois grupos focais, o primeiro com dez participantes, com três homens e sete mulheres, e média 
de idade de 45 anos, e o segundo com oito participantes, sendo apenas um homem, e média de idade de 54 anos. A amostra foi escolhida por conveniência.

\section{LOCAIS}

A opção por se estudar e comparar duas localidades pertencentes a Regiões Administrativas (RAs) distintas se justifica pelo fato de o nível socioeconômico dos moradores e diferenças na composição dos ambientes das mesmas serem possíveis fatores que influenciam o consumo de água e apego ao lugar (del Grande, Galvão, Miranda e Sobrinho, 2016). O racionamento de água pode afetar de diferentes maneiras e intensidades populações de diferentes níveis sociais, pelas necessidades e pelos recursos disponíveis aos moradores das diferentes moradias.

\section{INSTRUMENTOS}

Foi aplicado aos participantes um questionário, que se dividia em três partes. A primeira parte acessava atitudes dos participantes em relação ao racionamento de água. Esta primeira seção do questionário era composta por uma pergunta sobre o racionamento, "O quanto você concorda com o racionamento de água na cidade", com uma escala do tipo Likert de 1 a 10 . A segunda pergunta era uma questão discursiva, que indagava qual a opinião do participante sobre o racionamento de água. A segunda parte do questionário, relativa ao apego ao lugar de residência, continha uma escala de nove itens, que buscava verificar a intensidade do apego do participante a sua casa, vizinhança e cidade ${ }^{27}$.

Além dos questionários, foram realizados grupos focais, para se acessar, identificar e compreender percepções, atitudes e representações dos participantes sobre o racionamento de água e sobre suas relações com o lugar onde moravam.

\section{PROCEDIMENTOS}

Na Localidade 1 foi realizado um grupo focal e em Localidade 2 foram realizados dois grupos focais, antes da aplicação dos questionários, para que o conteúdo dos grupos auxiliasse na construção dos questionários posteriormente. As discussões duraram, em média, 02 horas e ocorreram de forma semiestruturada, com perguntas-chave sobre apego ao lugar, vivências nas casas, vizinhança e cidade, e sobre o racionamento de água sendo apresentadas para guiar a discussão, que foi moderada pela própria pesquisadora. A formulação de perguntas para a discussão sobre apego ao lugar de moradia se baseou na estruturação do construto e organização de pesquisas sobre o tema proposta por Scannell e Gifford, (2010). Estes autores concebem apego ao lugar como um construto multidimensional, composto pelas dimensões "Pessoa", "Lugar" e "Processos Psicológicos".

A escala de apego ao lugar de moradia foi traduzida do inglês para o português e teve tradução verificada por duas pessoas fluentes na língua inglesa. Foi realizado um pré-teste do questionário com seis pessoas, três moradores da Localidade 1 e três moradores de Localidade 2 . Houve modificações na formulação de uma pergunta acerca do número de residentes em cada casa, e nos termos utilizados nas perguntas da escala de apego ao lugar, para que se tornassem mais facilmente compreendidas. Os questionários foram aplicados de maneira presencial, porta a porta, em ambas as localidades. Os questionários foram aplicados de maneira presencial, porta a porta, em ambas as localidades. A aplicação ocorreu de abril, após a realização dos grupos focais, até o fim do racionamento de água, em junho de 2018.

Em Localidade 2 foi necessário, em algumas ocasiões, que as perguntas do questionário fossem lidas aos participantes, uma vez que os mesmos não eram alfabetizados. Também em Localidade 2 a quantidade de participantes que não informaram a faixa de renda foi alta e, portanto, para análise estatística essa variável foi excluída e em seu lugar foi considerado o nível de escolaridade.

\section{ANÁLISE DE DADOS}

Foi realizada análise de conteúdo para os dados dos grupos focais. Para este fim foi utilizado o software IRaMuTeQ (Interface de $\mathrm{R}$ pour les Analyses Multidimensionelles de Textes et de Questionnaires), a partir da gravação de áudio das falas dos participantes 
por ocasião dos grupos focais. Assim, após transcrição dos áudios dos grupos focais, foi utilizado o programa para se verificar quais as classes surgiriam a partir das falas dos participantes, quais palavras mais utilizadas, e como se relacionavam entre si, para se compreender as percepções acerca do racionamento e de como é viver nos locais onde os participantes moram, e como ocorre o vínculo entre pessoas, grupos, e lugar de moradia. O programa também foi utilizado para se analisar as perguntas abertas presentes na seção de racionamento do questionário, para se obter informações adicionais sobre opinióes e atitudes de moradores em cada bairro sobre o racionamento.

Foi utilizado o software estatístico Statistical Package for the Social Sciences (SPSS), versão 21.0, para realizar as análises estatísticas das escalas e perguntas sociodemográficas, considerando nível de significância de $5 \%$ e intervalo de confiança de $95 \%$. Para verificar se existia correlação entre apego ao lugar e a favorabilidade ao racionamento de água foi realizada análise do coeficiente de correlação de Spearman. O teste de Mann-Whitney foi utilizado para comparar as médias apresentadas das variáveis em relação aos locais estudados.

Para as variáveis que não apresentassem apenas dois grupos, como sexo, foi conduzido o teste estatístico de Kruskal-Wallis, que cumpre a função de comparar diversos grupos, sem a necessidade de se conduzir diversos testes Mann-Whitney, uma vez que quanto mais testes são realizados, maiores as chances de ocorrer o Erro Tipo ${ }^{28}$.

\section{RESULTADOS}

\section{ANÁLISE DOS DADOS DOS QUESTIONÁRIOS}

Na Localidade 1, a média de idade foi de 50,9 anos, com desvio padrão $(D P)$ de 20,6, a média de idade foi de 34,8 anos, a média do número de adultos por residência foi de 3,65 , e a média do número de crianças por residência foi de 0,44 . Em Localidade 2 , a média de idade foi de 34,8 anos. A média do número de adultos por residência foi de $3,57, D P=1,84$, e a média do número de crianças por residência foi de $1,00, D P=0,9$. A Tabela 1 revela os resultados das análises descritivas para as perguntas sociodemográficas dos questionários.

\section{Escala - Apego ao Lugar}

Em relação às médias de Apego ao Lugar, participantes residentes da Localidade 1 demonstraram ser mais apegados a seus locais de moradia do que participantes que residem em Localidade 2, em todos os níveis de apego. O maior nível de apego na Localidade 1 foi em relação ao Apego Físico ( $\mathrm{M}=9,70, \mathrm{DP}=1,68)$, e o menor nível foi em relação ao Apego Social ( $M=$ $8,91, \mathrm{DP}=1,97)$. Em Localidade 2, o maior nível foi em relação à casa $(\mathrm{M}=7,78, \mathrm{DP}=2,38)$, e o menor foi em relação ao Apego Físico $(M=7,05, \mathrm{DP}=2,42)$.

$\mathrm{Na}$ Localidade 1, não se correlacionaram apenas o Apego à cidade e a Casa. A correlação mais forte ocorreu entre Apego Geral e Apego a Casa $(r=0,827, p<0,001)$, e a correlação mais fraca foi aquela entre Apego Geral e Apego à cidade $(r=0,423, p<0,001)$. Em Localidade 2 , todos os itens das escalas estão correlacionados positivamente entre si. A correlação mais forte ocorreu entre Apego Geral e Apego à Localidade $2(r=0,867, p<$ $0,001)$, e a mais fraca entre Apego Físico e Apego Social $(r$ $=0,579, p<0,001)$.

\section{ANÁLISES ESTATÍSTICAS DOS QUESTIONÁRIOS}

Ao serem analisadas as respostas conjuntas de ambas as localidades, Localidade 1 e Localidade 2, o teste de correlação de Spearman revelou não haver correlação entre favorabilidade às medidas de racionamento de água e Apego ao lugar. Houve correlação positiva entre o número de crianças na residência e favorabilidade às medidas de racionamento $(r=0,207, p<0,05)$. O teste também indicou que o Apego Geral foi maior em participantes que residem há mais tempo em suas casas $(r$ $=0,224, p<0,05)$, localidades de residência, Localidade 1 ou Localidade $2(r=0,257, p<0,01)$ e na cidade $(r=$ $0,349, p<0,001)$

Em relação à Localidade 1, O teste de correlação de Spearman revelou correlação positiva entre idade e Apego Geral $(r=0,583, p<0,001)$, e entre idade e apego à casa $(r=0,522, p<0,001)$.

Os testes de Mann-Whitney para amostras 
independentes revelaram que moradores da Localidade 1 apresentam maiores escores para Apego Geral $(U=$ $1.878,5, p<0,001, r=0,4)$, Apego Físico $(U=2.095, p$ $<0,001, r=0,53)$, Apego Social $(U=1.753, p<0,01$, $r=0,3)$, Apego a Casa $(U=1.734,5, p<0,01, r=0,3)$, Apego a Asa Norte $(U=2.000, p<0,001, r=0,47)$, e Apego ao Distrito Federal $(U=1.908, p<0,001, r$ $=0,41)$. O teste de Mann-Whitney também revelou que participantes da Localidade 1 que possuem casa própria demonstram maior Apego Geral $(U=128,5, p<0,05)$ e maior Apego à Casa $(U=138,5, p<0,05)$.

$O$ teste de Kruskal-Wallis indicou que os participantes residentes na Localidade 1 , detentores de ensino superior completo demonstraram ter mais Apego à Asa Norte $(H(2)=12,26, p<0,05)$, e que o Apego à Casa é maior quando a própria pessoa é responsável pela organização da mesma $(H(2)=6,96, p<0,05)$.

\section{FAVORABILIDADE ÀS MEDIDAS DE RACIONAMENTO}

Quanto à pergunta acerca da favorabilidade ("Qual a sua opinião sobre as medidas de racionamento de água vigentes no Distrito Federal?"), a média total de favorabilidade foi de $6,89, \mathrm{DP}=3,11.70,9 \%$ do total de participantes responderam ser favoráveis às medidas, apontando na escala valores entre 6 e 10. Na Asa Norte, $86 \%$ se mostraram favoráveis, com uma média de 7,77, DP $=2,23$. Em Santa Maria 60\% dos participantes afirmaram ser favoráveis às medidas de racionamento, apresentando uma média de 6,27, DP = 3,49. A análise estatística de Mann-Whitney não indicou diferença significativa sobre a questão de favorabilidade entre as duas localidades.

Entre os moradores de Localidade 2, a análise dos resultados indicou uma correlação negativa entre apego ao DF e favorabilidade às medidas de racionamento $(r$ $=-0,335, p<0,01)$. O teste de correlação de Spearman também revelou que quanto maior o número de residentes, maior a favorabilidade às medidas de racionamento $(r=$ $0,273, p<0,05)$. Ainda entre residentes da Localidade 2 , o teste de Kruskal-Wallis indicou que participantes que completaram o ensino médio se mostraram mais favoráveis às medidas de racionamento do que os participantes com outros níveis de escolaridade $(H(2)=11,5, p<0,05)$, e que a favorabilidade às medidas de racionamento é maior entre participantes que são responsáveis pelas decisões de organização da própria casa $(H(2)=6,47, p, 0,05)$. 0 teste de Kruskal-Wallis revelou que entre os participantes de Santa Maria, o Apego à Casa é maior quando o mesmo relata possuir amigos próximos ao local onde mora $(H(2)$ $=6,63, p<0,05)$.

Os testes de Mann-Whitney para amostras independentes revelaram que moradores da Localidade 1 apresentaram maiores escores para Apego Geral $(U=$ $\left.1.878,5, p<0,001^{* * *}, r=0,4\right)$, Apego Físico $(U=2.095$, $\left.p<0,001^{* * *}, r=0,53\right)$, Apego Social $(U=1.753, p<$ $\left.0,01^{* *}, r=0,3\right)$, Apego a Casa $\left(U=1.734,5, p<0,01^{* *}\right.$, $r=0,3)$, Apego a Localidade $1(U=2.000, p<0,001 * * *$, $r=0,47)$, e Apego a Cidade $\left(U=1.908, p<0,001^{* * *}, r\right.$ $=0,41)$. O teste de Mann-Whitney também revelou que participantes da Localidade 1 que possuem casa própria demonstraram maior apego geral $(U=128,5, p<0,05)$ e maior apego a casa $(U=138,5, p<0,05)$.

\section{ANÁLISE DOS DADOS DOS GRUPOS FOCAIS}

As próximas sessões apresentam os resultados das análises realizadas pelo software IRAMUTEQ, primeiro para os grupos focais e, posteriormente, para as respostas discursivas dos questionários acerca da favorabilidade às medidas de racionamento. As figuras exibem os resultados da Classificação Hierárquica Descendente (CHD)

\section{Localidade 1:}

\section{Classificação Hierárquica Descendente (CHD)}

A Figura 1 apresenta a Classificação Hierárquica Descendente para a Localidade 1 , que revelou quatro classes. As Classes 1 e 3, que possuem representatividade de $24,8 \%$ e $19,1 \%$, respectivamente, encontram-se mais relacionadas entre si do que as Classes 2 e 4 . Pode-se dizer que ambas as classes dizem respeito ao racionamento, à gestão dos recursos hídricos e às percepções acerca dos mesmos, com palavras como "água", "poço", "caixa de água" e "conscientização", "usar" e "falta" sendo proeminentes. 


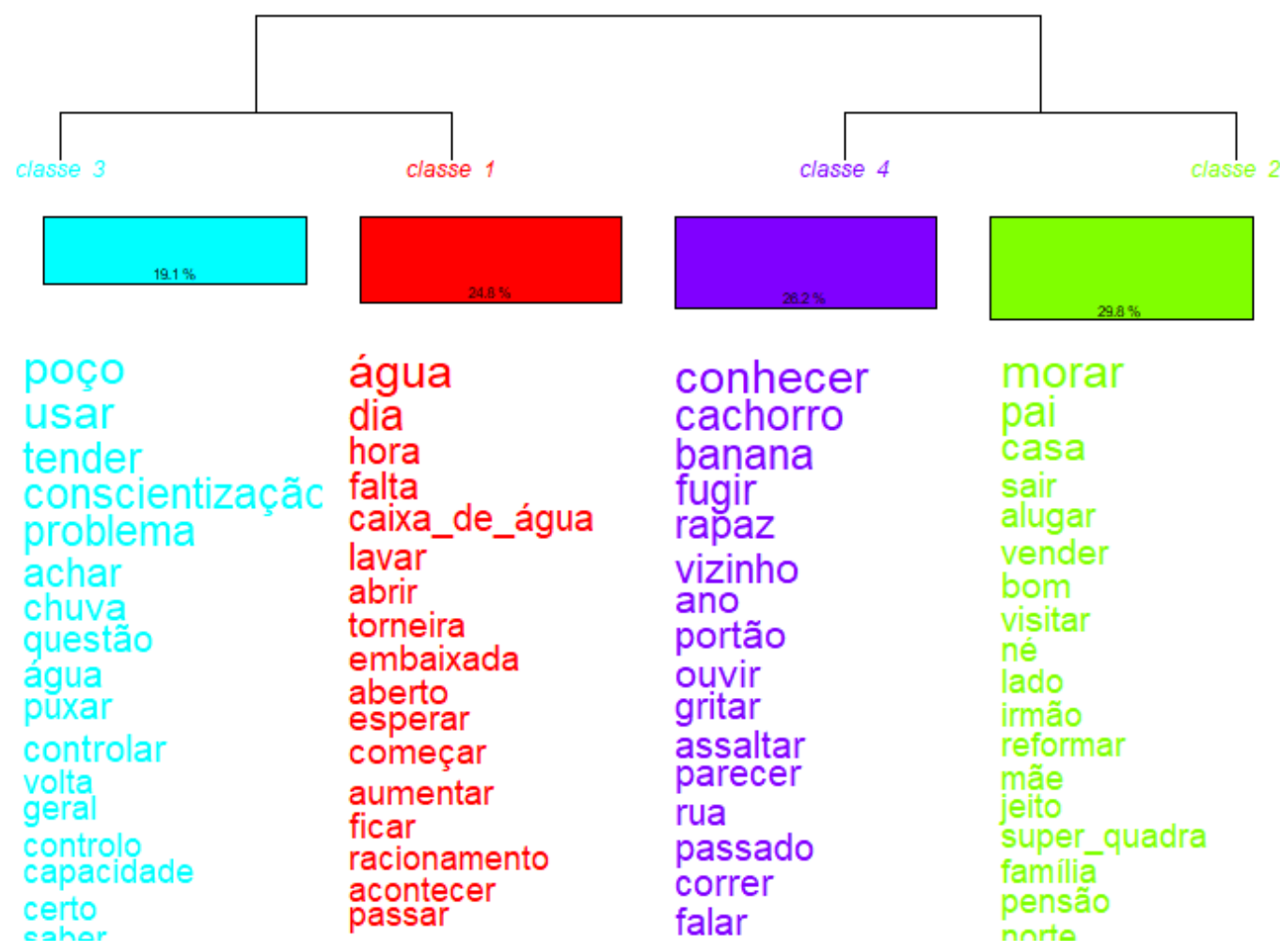

Figura 1. Classificação Hierárquica Descendente (CHD) para Localidade 1.

A Classe 1 está mais associada às rotinas dos participantes quanto ao racionamento de água, quais foram as principais adaptações e as dificuldades encontradas durante o período de racionamento:

Agora tem um outro detalhe sobre isso, essa falta de água. É que além de demorar dois dias, muitas vezes vem com tanto barro que a gente não pode utilizar, e quando utiliza mancha a roupa (Mulher, 50 anos).

A Classe 3 também está relacionada ao racionamento, no entanto, seu conteúdo principal diz respeito a percepções sobre como outras pessoas têm se comportado durante o racionamento, sobre a necessidade de se economizar água, e melhorias que deveriam ser feitas na gestão dos recursos hídricos na cidade, principalmente em relação à fiscalização:

Tem gente fazendo gambiarra, usando água, essa é a verdade. E vistoria aqui fora da cidade não tem. Aqui é mais vigente, é mais controlado (Homem, 68 anos).

A Classe 2 tem representatividade de $29,8 \%$ e possui termos relativos à dinâmica de como é morar onde se mora, e o que está associado a este contexto, com termos como "morar", "pai", "casa", "sair", "alugar" e "bom" em evidência. A Classe 4, que possui representatividade de 26,2\%, apesar de estar mais relacionada a Classe 2, não apresenta, em sua maioria, termos similares aos da Classe 2, mas palavras relacionadas a acontecimentos que já ocorreram naquela localidade, como "fugir", "gritar" e "assaltar". Mais especificamente, a Classe 2 é composta por percepções de como é para os participantes morar na Localidade 1, e em suas casas, e quais as razões de gostarem ou não de morar ali:

Para nós isso daqui foi uma maravilha, né, porque facilitou a vida da gente. Antes eram duas boras de carro, de ônibus, metrô, e agora aqui não" (Mulher, 50 anos).

A Classe 4 abrange as relações de vizinhança dos participantes:

Também nunca nos metemos em nada. O vizinho quem faz é você, né, e se você briga, o vizinho vai brigar, se não briga, o vizinho não vai brigar (Homem, 68 anos). 


\section{Localidade 2}

$\mathrm{Na}$ Figura 2 é possível observar as cinco classes geradas pela CHD. As Classes 2 e 4, com representatividade de, respectivamente, $23,8 \%$ e $14 \%$, encontram-se mais relacionadas entre si do que as demais classes. Estas classes dizem respeito a história dos participantes em Localidade 2, e aos principais componentes das experiências vividas naquela localidade, como indicam as palavras "morar", "gosto", "amar", "nascer", "filho", "conversar", "deus", "neto", "criança".

\begin{tabular}{llllll|}
\cline { 3 - 4 } & & & & \\
\end{tabular}

Figura 2. Classificação Hierárquica Descendente (CHD) para Localidade 2.

A Classe 2 representa temas como pontos positivos e negativos da cidade e Localidade 2 , e as relações sociais estabelecidas nesses locais:

Cada um tem sua vida, cada um tem seu emprego, dia a dia corrido, né, ninguém se vê, difícil. Os vizinbos são pessoas boas, né, eu mesmo essas aqui são minhas vizinhas, e a gente está sempre junta, o que uma precisa uma ou outra ajuda (Mulher, 38 anos).
Ainda que a Classe 2 mostre críticas à Localidade 2, a Classe 4 é composta por afirmações sobre a relação afetiva positiva entre os participantes e Localidade 2 :

Aquiéque é теu lugar, aquique eu amo. Vim com meu marido e ainda tive o privilégio de ganhar mais um filbo aqui (Mulher, 71 anos).

A Classe 3, com 18,2\% de representatividade, é composta principalmente por termos associados ao uso da água e ao racionamento, como pode ser observado a partir das palavras que emergiram, "água", 
"caixa de água", "usar", "balde", "encher", "chuva", "banho" e "economizar". Diz respeito ao uso e racionamento de água no período em que as medidas foram implementadas, e quais as adaptações realizadas e quais as percepções dos participantes:

Só que eu falo uma coisa para vocês esse racionamento veio para gastar mais água. Porque o povo armazena um monte de água e termina não usando. É verdade, e essa água vai jogada fora porque ela fica velha, aí acumula (Mulher, 60 anos).

As Classes 1 e 5, por sua vez, possuem representatividade de, respectivamente, $25,2 \%$ e $18,9 \%$. Em ambas, temas associados a insatisfação com a gestão do governo são recorrentes. Ambas são compostas por críticas à gestão do racionamento, falta de participação social nas decisões governamentais, e crenças sobre a escassez de água e racionamento:

Eu acho que o governo tinha que se preparar melhor. Só dois reservatórios para atender a população, que foi programada para $x$ pessoas, e boje você vê que a população, assim, tá de forma descontrolada, né" (Homem, 33 anos).

\section{RESPOSTAS DISCURSIVAS}

Para identificar quais as principais palavras $\mathrm{e}$ termos utilizados pelos participantes para descrever suas percepções acerca do racionamento foi utilizada a Nuvem de Palavras, construída pelo IRAMUTEQ. A análise foi feita a partir das respostas de ambas as localidades.

As palavras mais frequentes, como pode ser observado na Figura 3, foram "água" e "racionamento", acompanhadas de palavras que demonstram favorabilidade às medidas, como "necessário", "bom", "economizar", "concordar", "conscientizar" e "ótimo". Palavras desfavoráveis ao racionamento obtiveram menor proeminência, como as palavras "ruim", "desnecessário" e "acabar".

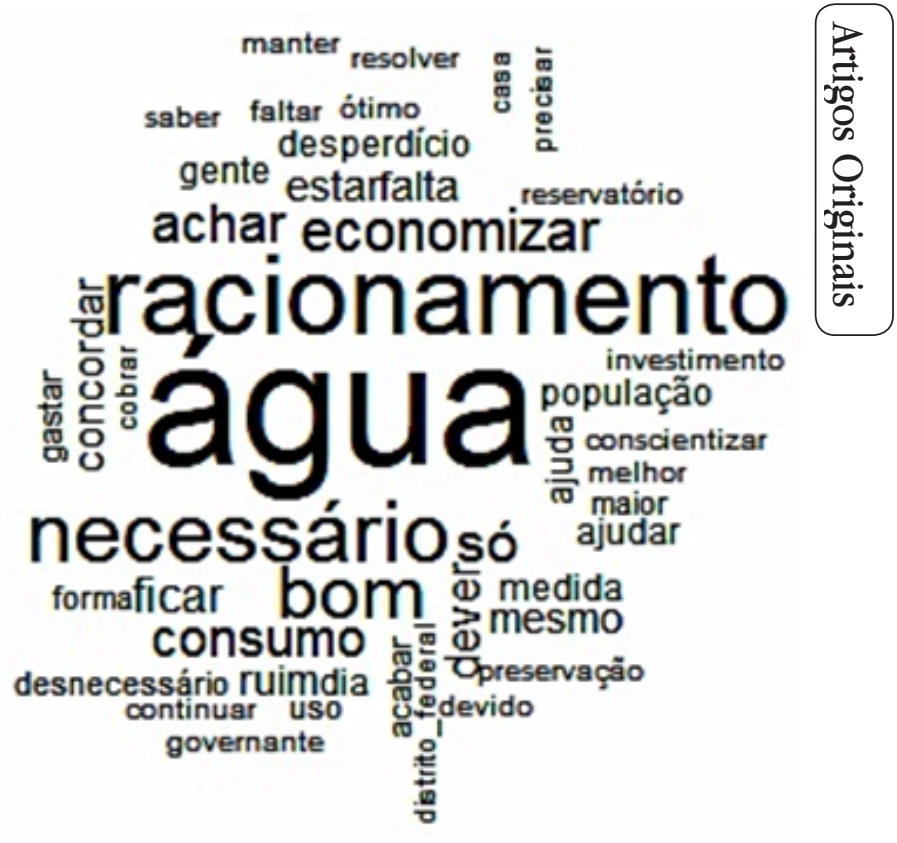

Figura 3. Nuvem de Palavras de respostas discursivas das Localidades 1 e 2.

\section{DISCUSSÃO}

As respostas aos questionários apontam que mais de $70 \%$ dos participantes declararam ser favoráveis às medidas de racionamento de água implementadas. Costuma-se encontrar que quanto maior a distância física e temporal entre o indivíduo e o risco ambiental e suas consequências, menor a gravidade atribuída a este risco 29. O inverso também ocorre, ou seja, a proximidade ao local de risco está correlacionada a maior frequência de ações que visem evitar ou mitigar o risco, nesse caso, a escassez de água ${ }^{11}$. Os residentes da cidade sentem há algum tempo, e especialmente nos últimos dois anos, o risco real da escassez de água e suas consequências, o que pode explicar a alta favorabilidade às medidas de racionamento. O risco da escassez de água foi propagado amplamente pelo governo e mídia, e, portanto, é possível que a eminência deste risco tenha influenciado as percepções e atitudes dos respondentes.

O risco da escassez de água foi propagado em larga escala pelo governo e mídia, e então se supõe que a eminência deste risco tenha influenciado a percepção e atitude dos respondentes, resultando na alta favorabilidade às medidas e, consequentemente, à ausência de correlação entre favorabilidade e apego ao lugar. Sendo poucos os casos em que os participantes 
se mostravam desfavoráveis, não houve grande variação no nível da variável favorabilidade, o que pode explicar a ausência de correlação positiva entre apego ao lugar de moradia e favorabilidade às medidas de racionamento de água. Outro fator que deve ser levado em consideração é a possibilidade da desejabilidade social ter influenciado as respostas dos participantes aos questionários. A desejabilidade social é um tipo de enviesamento de respostas, em que respondentes atribuem a si mesmos valores, atitudes e comportamento socialmente desejáveis ou positivos. Atualmente, comportamentos pró-ambientais têm sido cada vez mais reconhecidos como comportamentos positivos e valorizados, o que pode ter influenciado os participantes em suas respostas sobre o racionamento de água.

Apesar da alta favorabilidade, um tema recorrente nos grupos focais em ambas as localidades, e que foi proeminente nas classes encontradas pelo IRAMUTEQ tanto na Localidade 1 quanto em Localidade 2, foi a insatisfação com o governo e autoridades no sentido de fiscalização do cumprimento das medidas, e da forma como foi efetivado o racionamento. Os participantes criticaram a inutilidade de se conservar água em suas residências ao mesmo tempo em que outros moradores de suas localidades e de outras mais afastadas desperdiçavam água e até mesmo se apropriavam deste recurso de maneira ilegal.

As discussões durante os grupos focais demonstram que fatores ambientais, como a falta de chuvas, não foram as únicas causas encontradas pelos participantes para o risco de escassez de água. Problemas como falta de planejamento e infraestrutura, desconfiança em relação ao governo, crescimento acelerado da população, uso indevido de áreas rurais e de preservação foram considerados agravantes para a situação de risco de falta de água. A construção de poços artesianos, ausência de punição a quem capta e gasta água indevidamente, e injustiça percebida na forma de se cobrar ou recompensar o maior ou menor uso de água em cada residência foram temas recorrentes relacionados à insatisfação com a forma que o racionamento foi realizado.

Ainda que a maioria das pessoas apoiasse as medidas e percebesse a necessidade de se conservar o recurso, havia muitas críticas em relação ao papel do governo para que a crise hídrica chegasse a um nível crítico. A falta de confiança na gestão governamental desta política pública e simultânea percepção de injustiça podem fazer aflorar em moradores afetados pelo racionamento desconfianças em relação a governo e a própria eficácia das medidas, dificultando a adesão e aceitação do público ${ }^{11,9}$.

Apesar de favoráveis às medidas de racionamento, grande parte dos participantes dos grupos focais relatou ter adquirido caixas de água maiores para o período de racionamento. Apesar das declarações de que a economia de água em curto e longo prazo é necessária, quando colocados frente a possibilidade de desconforto e incertezas em decorrência a necessidade de se economizar o recurso, a maioria dos participantes optou por estocar mais água do que o normal. Apesar do entendimento de que os benefícios em longo prazo de se economizar água seriam vantajosos para todos, os participantes avaliaram, de forma consciente ou não, que os benefícios em curto prazo seriam mais recompensadores. Esta avaliação é comum frente a dilemas ou possibilidades de se comportar de maneira pró-ambiental, uma vez que o uso em excesso, ou a escolha por não realizar comportamentos de conservação costumam trazem na maioria das vezes consequências positivas mais imediatas ${ }^{22}$.

Nas duas localidades estudadas, classes relacionadas ao Apego ao Lugar de moradia surgiram, evidenciando os vínculos existentes entre moradores e seus locais de residência, em especial suas casas e vizinhanças. As respostas à escala de Apego ao Lugar revelaram diferenças nos níveis de apego, principalmente de acordo com a localidade. Participantes residentes da Localidade 1 se mostraram mais apegados aos seus lugares de moradia em todos os níveis da escala. As falas dos grupos focais e classes formadas pelo IRAMUTEQ corroboram este resultado, uma vez que moradores da Localidade 1 relataram menos experiências e percepções negativas acerca de sua vizinhança do que moradores de Localidade 2. As classes formadas para os grupos focais de Localidade 2 apontam que lá os participantes se mostraram insatisfeitos em diversos níveis, não só em relação ao racionamento, mas também à infraestrutura $\mathrm{e}$ à administração da Localidade 2.

A maior intensidade de apego ao lugar de 
moradia vem sendo associada a comportamentos e atitudes favoráveis à proteção ambiental ${ }^{12}$. Visto que nas respostas às escalas participantes da Localidade 1 reportaram forte apego ao lugar de moradia, e moradores de Localidade 2 demonstraram moderado para alto apego ao lugar, supóe-se que os altos níveis de apego expliquem em parte a alta favorabilidade às medidas de conservação de água.

A correlação positiva entre participantes que moravam há mais tempo em suas casas, vizinhanças e na cidade e favorabilidade às medidas de racionamento pode ser explicada pela apropriação do espaço por esses moradores, que provavelmente está mais estabelecida pelo fato de estarem morando há mais tempo no mesmo local. A apropriação do espaço está associada a sentimentos de pertencimento a um lugar e tendências a mantê-lo conservado, para que se mantenham as propriedades físicas, sociais e simbólicas do lugar, assim como a vinculação positiva existente entre a pessoa e o lugar ${ }^{11}$.

\section{CONCLUSÃO}

Apesar de apego ao lugar de moradia e favorabilidade às medidas de racionamento terem se correlacionado apenas em Localidade 2, de maneira negativa, e em participantes que revelaram maior apego ao lugar de moradia, as variáveis que se correlacionaram positivamente com favorabilidade foram aquelas que dizem respeito ao tipo de relação estabelecida entre pessoa e lugar de moradia.

Estudos que analisam a relação entre apego ao lugar e comportamento pró-ambiental ainda são incipientes, e é possível, portanto, que pesquisas que considerem apego ao lugar como uma variável mediadora ou moderadora na relação entre outras variáveis e adesão a comportamentos pró-ambientais, encontrem resultados mais significativos. Pela complexidade de ambos os construtos - apego ao lugar e comportamento pró-ambiental-, uma relação direta pode não apresentar significância, pelos diversos outros fatores influentes nesta relação.

O presente estudo apresenta limitações que podem interferir na generalização dos resultados, como o número limitado de participantes, e o fato da amostra ter sido escolhido por conveniência.

\section{REFERÊNCIAS}

1. United Nations Educational, Scientific and Cultural Organization (UNESCO). The United Nations World Water Development Report. França; 2018

2. Oskamp S. A sustainable future for humanity? How can psychology help? Amer. Psych. 2000;55(5): 496508. DOI: 10.1037//0003-066X.55.5.496

3. Carrus G, Bonaiuto M, Bonnes, M. Environmental concerns, regional identity, and support for protected areas in Italy. Env. Behav. 2005;37(2):23757. DOI: $10.1177 / 0013916504269644$

4. Brown BB, Perkins DD. Disruptions in place attachment. In: Altman, Low SM, organizadores. Place Attachment. Nova York: Plenum; 1992. p. 279304.

5. Burdruk M, Thomas H, Tyrell T. Urban green spaces: A study of place attachment and environmental atitudes in India. Soc. Nat. Resour. 2009; 22:824-39. DOI: $10.1080 / 08941920802628515$

6. Halpenny EA. Environmental Behaviour, Place Attachment and Park Visitation: A case study of visitors to Point Pelee National Park; 2006. Disponível em: http:/hdl.handle.net/10012/718

7. Larson LR. Stedman RC, Cooper CB, Decker DJ. Understanding the multi-dimensional structure of pro-environmental behavior. Journ. Env. Behav. 2015; 43:112-24. DOI: http://dx.doi.org/10.1016/j. jenvp.2015.06.004

8. Steg L, Vlek C. Encouraging pro-environmental behaviour: An integrative review and research agenda. Jour. Env. Behav. 2009; 29:309-17. DOI: 10.1016/j.jenvp.2008.10.004

9. Gifford R, Nilsson A. Personal and social factors that influence pro-environmental concern and behaviour: A review. Int. Jour. Psych. 2014; 49(3):141-57. DOI: 10.1002/ijop. 12034

10. Jaeger CM, Schultz PW. Coupling social norms and commitments: Testing the underdetected nature of social influence. Jour. Env. Psych. 2017.

11. Corral-Verdugo V, Bechtel RB, Fraijo-Sing B. 
Environmental beliefs and water conservation: An empirical study. Jour. Env. Psych. 2003; 23:247-57.

12. Lewicka M. What makes neighborhood different from home and city? Effects of place scale on place attachment. Jour. Env. Psych. 2010; 30:35-51. DOI: 10.1016/j.jenvp.2009.05.004

13. Winter DN, Koger SM. The Psychology of Environmental Problems. Psych. Press. 2004.

14. Oskamp S. Environmentally Responsible Behavior: Teaching and Promoting It Effectively. Anal. Soc. Issu. Publ. Pol. 2002; 1:173-82.

15. Aprile MC, Fiorillo D. Water conservation behavior and environmental concerns; evidence from a representative sample of Italian individuals. Jour. Clean. Prod. 2017.

16. Pato C, Ros M, TamayoA. CreenciasyComportamiento Ecológico: un studio empírico con estudiantes brasileños. Med. Amb. Comp. Hum. 2005; 6(1):5-22.

17. Dolnicar S, Hurlimann A, Grun B. What affects public acceptance of recycled and desalinated water? Wat. Res. 2011; 45:933-43. DOI: 10.1016/j. watres.2010.09.030

18. Coelho JAPM, Gouveia VV, Souza GHS, Milfont TL, Barros BNR. Emotions toward water consumption: Conservation and wastage. Rev. Latinoam. Psi. 2016; 48:117-26. DOI: http://dx.doi.org/10.1016/j. rlp.2015.09.006

19. Gregory GD, Di Leo M. Repeated behavior and environmental psychology: The role of personal involvement and habit formation in explaining water consumption. Jour. Appli. Psych. 2003;33(6):1261-1296.

20. 20.Lewicka M. Ways to make people active: The role of place attachment, cultural capital, and neighborhood ties. Jour. Env. Psych. 2005; 25:38195. DOI:10.1016/j.jenvp.2005.10.004

21. Randolph B, Troy P. Water Restrictions as way of Moderating Demand. SOAC. 2017.

22. Nolan JM, Schultz PW, Cialdini RB, Goldstein NJ, Griskevicius V. Normative Social Influence is Underdetected. Pers. Soc. Psych. Bull. 2008; 34(7):913-23. DOI: $10.1177 / 0146167208316691$

23. Eriksson L, Garvill J, Nordlund A. Acceptability of travel demand management measures: The importance of problem awareness, personal norm, freedom, and fairness. Jour. Env. Psych. 2006; 26:1526.

24. Quinn T, Lorensoni I, Adger WN. Place attachment, identity, and adaptation. In: O'Brien K, Selboe E, organizadoras. The Adaptive Challenge of Climate Change. Cambridge University Press; 2015.

25. Brehm JM, Eisenhauer BW, Krannich RS. Community Attachments as Predictors of Local Environmental Concern: The Case for Multiple Dimensions of Attachment. Americ. Behav. Scient. 2006; 50(2):14265. DOI: $10.1177 / 0002764206290630$

26. Vorkinn M, Riese H. Environmental Concern in a Local Context: The Significance of Place Attachment. Env. Behav. 2001; 33:249-63. DOI: $10.1177 / 00139160121972972$

27. Hidalgo MC, Hernández B. Place attachment: Conceptual and empirical questions. Jour. Env. Psych. 2001;3:273-281.DOI: https://doi.org/10.1006/ jevp.2001.0221

28. Field A. Discovering Statistics Using IBM SPSS Statistics. SAGE.

29. Bohm G, Tanner C. Environmental risk perception. In:Steg L, van den Berg AE, Groot JIM. Environmental Psychology: An Introduction. BPS Blackwell.

Recebido em: 15/01/2019

Aceito em: 20/08/2019 